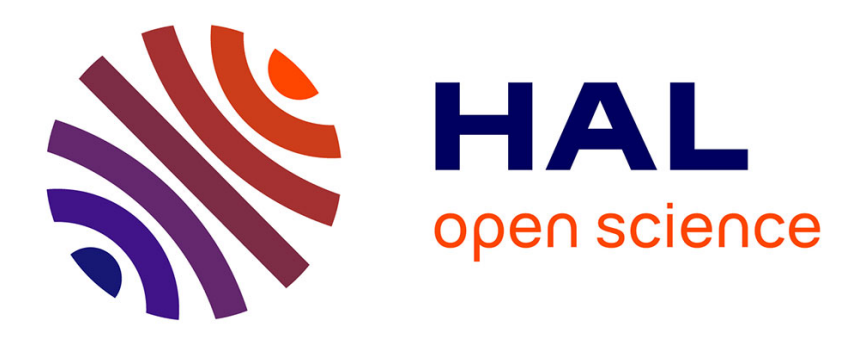

\title{
Botallo's error, or the quandaries of the universality assumption
}

Paolo Bartolomeo, Tal Seidel Malkinson, Stefania de Vito

\section{To cite this version:}

Paolo Bartolomeo, Tal Seidel Malkinson, Stefania de Vito. Botallo's error, or the quandaries of the universality assumption. Cortex, 2017, 86, pp.176 - 185. 10.1016/j.cortex.2016.09.026 . hal01494443

\section{HAL Id: hal-01494443 \\ https://hal.sorbonne-universite.fr/hal-01494443}

Submitted on 23 Mar 2017

HAL is a multi-disciplinary open access archive for the deposit and dissemination of scientific research documents, whether they are published or not. The documents may come from teaching and research institutions in France or abroad, or from public or private research centers.
L'archive ouverte pluridisciplinaire HAL, est destinée au dépôt et à la diffusion de documents scientifiques de niveau recherche, publiés ou non, émanant des établissements d'enseignement et de recherche français ou étrangers, des laboratoires publics ou privés. 


\section{Botallo's error, or the quandaries of the universality assumption}

\section{Paolo Bartolomeo $^{1}$, Tal Seidel-Malkinson ${ }^{1,2}$, Stefania de Vito ${ }^{1}$}

${ }^{1}$ INSERM U 1127, CNRS UMR 7225, Sorbonne Universités, and Université Pierre et Marie CurieParis 6, UMR S 1127, Institut du Cerveau et de la Moelle épinière (ICM), F-75013 Paris, France.

${ }^{2}$ The Hebrew University of Jerusalem, Jerusalem, Israel.

Acknowledgments: Supported by the program "Investissements d'Avenir" ANR-10-IAIHU-06, by a fellowship of the Israeli Science Foundation (TSM) and by the ERC POSITION - GA n 324070 (PB and SDV). 


\begin{abstract}
One of the founding principles of human cognitive neuroscience is the so-called universality assumption, the postulate that neurocognitive mechanisms do not show major differences among individuals. Without negating the importance of the universality assumption for the development of cognitive neuroscience, or the importance of single-case studies, here we aim at stressing the potential dangers of interpreting the pattern of performance of single patients as conclusive evidence concerning the architecture of the intact neurocognitive system. We take example from the case of Leonardo Botallo, an Italian surgeon of the Renaissance period, who claimed to have discovered a new anatomical structure of the adult human heart. Unfortunately, Botallo's discovery was erroneous, because what he saw in the few samples he examined was in fact the anomalous persistence of a fetal structure. Botallo's error is a reminder of the necessity to always strive for replication, despite the major hindrance of a publication system heavily biased towards novelty. In the present paper, we briefly discuss variations and anomalies in human brain anatomy and introduce the issue of variability in cognitive neuroscience. We then review some examples of the impact on cognition of individual variations in (1) brain structure, (2) brain functional organization and (3) brain damage. We finally discuss the importance and limits of single case studies in the neuroimaging era, outline potential ways to deal with individual variability, and draw some general conclusions.
\end{abstract}




\section{Introduction}

One of the founding principles of human cognitive neuroscience is the postulate that neurocognitive mechanisms do not show major differences among individuals. This postulate is often referred to as the universality assumption (Caramazza, 1986). In a recent formulation, the universality assumption stipulates that "there is no qualitative variation across neurologically intact people in the architecture of the cognitive system that these people use to perform in a certain cognitive domain. This allows us to infer that, although patient $\mathrm{X}$ and patient $\mathrm{Y}$ currently have very different systems as a consequence of their brain damage, they had the same system premorbidly, and it is about that system that we want to make inferences from studying patients $\mathrm{X}$ and $\mathrm{Y}$. Cognitive neuropsychology cannot be practiced unless this universality assumption is made, but nor can cognitive psychology. This is how, even though every patient is essentially unique, we can seek generalizable knowledge from studying them" (Caramazza and Coltheart, 2006, p. 6).

Without negating the importance of the universality assumption for the development of cognitive neuroscience, or the importance of single-case studies, this paper aims at stressing the potential dangers of interpreting the patterns of performance of single patients as conclusive evidence concerning the architecture of the intact neurocognitive system.

Importantly, similar issues have been extensively discussed in the context of other disciplines, such as normal human anatomy, whose evolution may help cognitive neuroscience and neuropsychology not to lose track of individual differences when establishing the (reasonably) general principles of functioning of the mind/brain. Here, we want to highlight the issues lurking behind single-case studies and the potential contribution of variability in anatomy and function to their external validity limitations. After briefly discussing variations and anomalies in human anatomy (Section 2), we introduce the issue of variability in cognitive neuroscience (Section 3) and review some examples of the impact on 
cognition of individual variations in brain structure (Section 4), brain functional organization (Section 5) and brain damage (Section 6). We then discuss the importance and limits of single case studies (Section 7), outline potential ways to deal with the issues raised by individual variability (Section 8), and draw some general conclusions (Section 9).

\section{Norm and variation in human anatomy: the case of Leonardo Botallo}

Leonardo Botallo (ca. 1519-1587/1588, Fig. 1) studied medicine in Pavia and Padua and worked as a military surgeon in Italy and in France, where he was also one of the physicians of Charles IX. Although Botallo expressed his admiration for the work of Vesalius, the founder of modern human anatomy, and of other pioneer anatomists, he was by no means an anatomist by training.

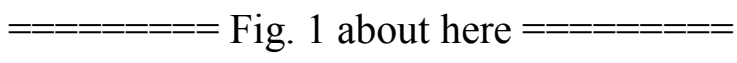

In 1564, Botallo published in Paris a treatise on hay fever (Botallo, 1564), at the very end of which he added a paragraph entitled Vena arteriarum nutrix a nullo antea notata ("The nutritious vein of the arteries, which nobody had remarked before”): “...I began to dissect the heart of a calf, in which I discovered... a channel... near the right auricle... that leads directly... to the left auricle. ... This pathway which I discovered is quite large and clearly visible in calves, pigs and dogs. In man instead it is a bit smaller..." (Botallo, 1564, pp. 94f). This description is thought to refer to one of two different anatomical structures, the foramen ovale or the ductus arteriousus (Fransson, 1999). Both are fetal structures that normally disappear in adult life. Botallo mistakenly generalized the casual discovery of an anatomical anomaly (the abnormal persistence of a fetal structure) to a characteristic of the normal adult anatomy. Botallo's error thus illustrates the potential danger of drawing general conclusions from a single case. 
An important distinction in anatomy is that between "normal" structures, which actually means "within the normal range of variations", and abnormal variations (Moore, 1989). An example of normal variation is the possible hypoplasia of some of the component arteries of the circle of Willis at the base of the brain. However, the presence of aneurisms in the same structure, while frequent, is definitely abnormal. Thus, frequency of occurrence is an important criterion of normality, but it is not a sufficient condition per se (Moore, 1989).

\section{Norm and variation in neuropsychology and cognitive neuroscience}

While the assumption of a substantial homogeneity of neurocognitive abilities across individuals has been important for the development of cognitive neuroscience, the time seems now ripe to start taking into account individual differences, as it is already the case for other disciplines such as human anatomy.

Recent technological and methodological developments have remarkably increased the spatiotemporal resolution and reliability of neuroimaging methods, even for single subjects. As a consequence, individual variability in behavioral performance, anatomical structure, and functional organization cannot be considered experimental noise any more, but should be deemed as a precious source of information for correlational studies (Kanai and Rees, 2011; Vogel and Awh, 2008). In parallel, statisticians have developed suitable methods to deal with single patients' individual patterns of performance, and to compare them to performance of groups of age-matched controls (e.g., Crawford and Garthwaite, 2002).

Cognitive neuropsychology and cognitive neuroscience, with their emphasis on possible causal connections between brain structure and function through the study of brain lesions, are subject to at least three sources of individual variations: variations in brain anatomy, in the brain functional organization, and in the lesion itself. 


\section{Cognitive consequences of variations in brain anatomy}

\subsection{Individual variations in brain anatomy}

Brain anatomy, like the anatomy of any other organ, shows a great deal of variability between individuals. There are important differences among the brains of "neurologically intact" people. The shape and size of the brain, the location of the sulci and gyri and their depth, the trajectories and volume of white matter tracts etc. show congenital individual differences, and are continuously modulated by mechanisms of plasticity throughout a person's life, reflecting individual experience. Most of the anatomical variations resemble each other, i.e. they are located near the center of the population's anatomical distribution, and are thus considered as normal (Moore, 1989). Even the brains of monozygotic twins are anatomically very similar, but not identical, in the morphology of gyri (Bartley et al., 1997) and sulci (Lohmann et al., 1999). Specifically, differences between "normal" brains impact connectivity patterns. For example, functional connectivity profiles may be described as different patterns of "connectome fingerprinting", which may allow identifying distinct individuals from a large group, with frontoparietal network emerging as the most distinctive connectivity pattern (Finn et al., 2015). Importantly, the individual connectome fingerprinting may be used to predict a cognitive trait such as fluid intelligence (Finn et al., 2015), and can have direct implications in language (Catani et al., 2007) and spatial processing (see Section 4.2 below). Also, variations in the structure of the left arcuate fasciculus can have cognitive relevance during reading acquisition. Fractional anisotropy in this tract correlated with reading ability and with phonological awareness in children, suggesting that it is a key component for the fast transmission of letter and sound information during literacy acquisition (Dehaene et al., 2015). Other examples of variations as a function of individual experience include the demonstration of changes in the structure of the left arcuate fasciculus with 
reading acquisition in adults (Thiebaut de Schotten et al., 2014a), the well-known case of London taxi drivers, whose hippocampal volume correlated with the amount of time spent in their professional activity (Maguire et al., 2000), and the structural changes in brain areas related to processing and storage of complex visual motion observed in people learning to juggle (Draganski et al., 2004).

Other anatomical variations might instead lead to pathological patterns of performance, such as in the case of congenital prosopagnosia, which has been associated with the individual degree of disruption in structural connectivity in the inferior longitudinal fasciculus and of the inferior fronto-occipital fasciculus in the right hemisphere (Thomas et al., 2009).

\subsection{The case of line bisection: How individual variations in the architecture of fronto-parietal networks can affect spatial cognition}

When we mark the midpoint of a horizontal line, we tend to err slightly towards the left of its geometric center (Bowers and Heilman, 1980; Jewell and McCourt, 2000). Bowers and Heilman (1980) called "pseudoneglect" the physiological leftward bisection error, because it occurs in the direction opposite to the rightward bias typical of patients with right hemisphere damage and signs of visual neglect (Urbanski and Bartolomeo, 2008). There is abundant psychophysical evidence that visuospatial attention is a major determinant of pseudoneglect (McCourt et al., 2005; Toba et al., 2011) ${ }^{1}$. Correspondingly, hemispheric asymmetries in the control of attention could be a major determinant of pseudoneglect (McCourt and Jewell, 1999; Ossandón et al., 2014). Using advanced methods of diffusion-

\footnotetext{
${ }^{1}$ Also cultural factors such as reading habits contribute to the direction and magnitude of pseudoneglect (Chokron and Imbert, 1993), thus providing a further important example of how individual differences can affect cognitive processing.
} 
based white matter tractography, Thiebaut de Schotten et al. (2011) demonstrated that larger volumes of a fronto-parietal tract in the right hemisphere, the second branch of the superior longitudinal fasciculus (SLF II), correlated with greater degrees of pseudoneglect, consistent with the hemispheric asymmetry hypothesis. Importantly, the three individuals who showed a paradoxical deviation towards the right side had an opposite pattern of lateralization, with larger volumes of left hemisphere SLF II. Thus, in this case, neuroimaging evidence of individual differences contributed to explain behavioral differences across individuals. Although correlation is not causation, these results strongly suggest that individual differences in the architecture of fronto-parietal attentional networks determine individual differences in patterns of psychophysical performance. Starting from these notions, it might be possible in principle to predict individual patterns of visuospatial performance on the basis of individual patterns of structural hemispheric asymmetries of the attentional networks.

One could for example conceive that in persons with strong right-left asymmetries of the attentional networks favoring the right hemisphere, the left endpoint of the line would be likely to capture attention on most trials, because of left-directing right hemisphere activity. Attention to the left endpoint would in turn provoke a relative overestimation of the length of the left line segment; as a consequence, the subjective midpoint would be placed closer to the left endpoint (pseudoneglect, see Toba et al., 2011). In persons with more symmetrical attention networks, however, either line endpoint would have similar chances of attracting attention for each trial, with consequent more symmetrical performance. 


\section{Variations in the functional organization of the brain}

\subsection{Individual variations in brain functional organization}

An additional layer of variability concerns the functional organization of the brain. To understand how a lesion to a particular brain site affected a certain cognitive function, the premorbid functional specialization of that region should be assessed. In general, the brain functional organization can be estimated using functional neuroimaging of task-based or resting state activity, employing methods such as functional MRI, EEG, or MEG. The aim of the classical approach to the study of functional organization was to understand the typical aspects of brain function, i.e. the norm, usually by averaging data across individuals to improve the signal-to-noise ratio. This approach, however, is inappropriate for the study of individual variations in brain functional organization (Dubois and Adolphs, 2016).

Mapping individual activation patterns for a given function is a complex task: it involves the matching of measured activation to the individual anatomy, with its possible structural variations discussed in the previous section. Moreover, the size of the individually measured signal may be very close to measurement noise, making its estimation difficult. Individual variations in vasculature may also be crucial for interpreting individual fMRI data. A person's BOLD signal depends not only on neural activity, but also on individual changes in cerebral blood flow, cerebral blood volume, and the cerebral metabolic rate of oxygen, as well as on the person's baseline physiological state. However, recent advances in fMRI data acquisition, improving the signal to noise ratio, together with better preprocessing and analysis tools, make the study of individual functional activation patterns an attainable challenge (Dubois and Adolphs, 2016).

Individual patterns of activation can be highly variable across individuals, as it can be seen in probabilistic activation atlases where each voxel has an attached probability value, 
reflecting how frequently it was activated across subjects during a certain task contrast (see, e.g., Wang et al., 2014). The functional organization of the normal brain not only varies across subjects but may also change within subjects. Kanai and Rees (2011) reviewed several examples of inter-individual variability in performance associated with differences in brain function.

Studying individual variability through functional neuroimaging is already showing some promising contribution in domains such as criminal justice, for which the use of neuroimaging to detect lies, for instance, may prove a valuable future application. But even at present, supporting evidence suggests such applications may be feasible. Individual differences in subjects' brain activation have been observed when bluffing vs. saying the truth during a card game (Langleben et al., 2002), in a memory task when honestly performing vs. simulating malingering (Chiu and Lee, 2002), or when discriminating veridical vs. false memories (Cabeza et al., 2001; for a commentary see Farah and Wolpe, 2004). Using decoding approaches, the individual patterns of brain activation in the scan may even allow researchers to identify the visual content of dreams (Horikawa et al., 2013).

\subsection{The case of literacy: How individual functional organization changes upon learning to read}

An example of how newly acquired skills shape brain functional mapping is the effect of learning to read on the organization of visually responsive brain areas. In literate people, the visual word form area (VWFA), a brain region specifically sensitive to words (Dehaene and Cohen, 2011), is always located next to a cortical region that is selective for faces: the left fusiform face area. Remarkably, within individual subjects, during reading acquisition, the boundary between these two regions was shown to shift. In illiterate individuals, the VWFA was strongly activated by stimuli other than words, such as pictures of faces, tools or checkerboards. As literacy increases, face responses undergo an inter-hemispheric displacement: 
face-induced fMRI responses in the left hemisphere become slightly smaller but increase substantially in the classical right-hemispheric face selective regions (Dehaene et al., 2010).

An analogous reorganization can be also observed after learning to read musical notation. Mongelli et al. (2016) had professional musicians and non-musician controls look at words and musical notation. Irrespective of musical expertise, musical notation induced selective activations posterior and lateral to activations for words in the VWFA. Thus, symbols characterized by different visual features engage distinct cortical areas. Interestingly, musical expertise increased the volume of activations for musical notation and shifted wordrelated activations antero-laterally. These findings suggest that individual variations in expertise can modulate the functional organization of category-selective areas in visual cortex, perhaps biasing competition between categories for the colonization of cortical space.

\section{Variations in brain lesions}

\subsection{Individual variations in lesion characteristics and in compensatory processes}

A third source of complexity for single case studies results from variability associated with brain lesions and their sequels. First, there is always some degree of uncertainty about the location and extent of brain lesions, as estimated by CT and MRI scans. Concerning vascular lesions, it has repeatedly been observed that the typical lesion mapping studies based on groups of patients are prone to substantial spatial distortions, caused by the fact that lesions do not follow the functional circuits of the brain, but rather the architecture of its vascular tree (Bartolomeo, 2011; Godefroy et al., 1998; Mah et al., 2014). Second, lesion-related changes in structural and functional connectivity to distant, anatomically intact brain areas (diaschisis, see Carrera and Tononi, 2014) further complicate lesion-symptom mapping. Thus, it is important to gather evidence across different etiologies (vascular, degenerative, neoplastic, 
traumatic), which do not share the same confounds in lesion-symptom mapping (Bartolomeo, 2011).

Third, there is a considerable variability in the brain reaction to the lesion. Some patients may show functional plasticity altering the organization of their brain to regain functional recovery, while others simply adopt behavioral strategies to compensate for their cognitive loss. These individual variations in the aftermath of brain damage pose an additional challenge when trying to estimate the cognitive effect of a lesion, especially when a long period has elapsed since its occurrence. Recovery from neurological and neuropsychological deficits may be more or less successful, also depending on the state of the system before the lesion. In particular, individual connectivity patterns might for example predict one's ability to compensate for deficits induced by brain damage. For instance, after unilateral brain damage the efficiency of connections within the healthy hemisphere and between the hemispheres might be crucial for the healthy hemisphere to engage in compensating cognitive deficits. In a group of aphasic patients with left hemisphere lesions, the volume of the long segment of the arcuate fasciculus in the right, non-lesioned hemisphere predicted recovery from aphasia (Forkel et al., 2014). These findings may depend at least in part on individual differences in pre-lesional brain structure, because individual patterns of connectivity may be more or less apt to allow vicariance of function in healthy nodes or networks (Bartolomeo and Thiebaut de Schotten, under review). Thus, a critical question is whether these variations result from differences in post-lesional compensation, or they reflect pre-existing individual variability in cerebral organization.

\subsection{The case of visual neglect: Individual patterns of damage and recovery in fronto-parietal attention networks}

Also relevant to these issues are pathological attention deficits, such as those occurring because of dysfunction of the fronto-parietal attention networks (Bartolomeo, 2014). When 
asked to bisect horizontal lines (see Section 2.2. above), neglect patients with damage to the attention networks in the right hemisphere mark the subjective midpoint to the right of the geometrical midpoint. This may be due to an overestimation of the right portion of the line (Urbanski and Bartolomeo, 2008), to a left underestimation (Charras et al., 2010), or both (Charras et al., 2012). The balance between these effects is likely to result from the interplay of activities of the right, damaged hemisphere and of the left, healthy hemisphere. Direct evidence on the implication of the human attention networks in line bisection was provided by Thiebaut de Schotten et al (2005), who showed that a transitory inactivation of SLF II during awake neurosurgery provoked massive rightward deviations on line bisection, similar to those produced by patients with severe visual neglect after right hemisphere strokes. These results were in broad agreement with lesion overlaps in previous group studies on stroke patients (Doricchi and Tomaiuolo, 2003; Leibovitch et al., 1998); however, in the neurosurgical study pathological performance during SLF II inactivation was only observed in a single patient, who was, moreover, left-handed and could thus have well had an idiosyncratic brain architecture $^{2}$. Thus, in order to be relevant to general neurocognitive models of attention and neglect, these results needed replication. Subsequent confirmatory evidence on the importance of fronto-parietal disconnection in neglect was obtained in stroke patients (Ciaraffa et al., 2013; Thiebaut de Schotten et al., 2014b; Urbanski et al., 2011; Verdon et al., 2006), and also in patients with neurodegenerative conditions such as posterior cortical atrophy (Andrade et al., 2013; Andrade et al., 2012; Migliaccio et al., 2012). Importantly, the awake surgery results were also directly replicated in several right-handed patients (Vallar et al., 2014).

But also the patterns of post-stroke recovery from visual neglect may be an important

\footnotetext{
${ }^{2}$ Actually, in this patient there was fMRI evidence for a partial representation of language in his right hemisphere; he was awakened during surgery also in order to preserve his language functions.
} 
source of variability. Lunven et al. (2015) recently showed that neglect patients who, in addition to the right hemisphere lesion, have DTI signs of structural changes in the splenium of the corpus callosum, are less likely to recover from neglect. Lunven et al. concluded that splenial disconnection may prevent fronto-parietal networks in the left hemisphere from resolving the activity imbalance with their right-hemisphere counterparts, thus leading to persistent neglect. At present, it is impossible to establish whether these differences in interhemispheric communication arose as a consequence of different lesions, or whether they were already present before the stroke occurred. Indirect evidence for pre-lesional difference comes from the above-mentioned study on language recovery after left hemisphere damage, showing that patients with a more bilateral structural network for language (as inferred from the structure of the arcuate fasciculi) were more likely to recover from aphasia than patients with more lateralized networks (Forkel et al., 2014). If so, then some individual brains might have a better predisposition to recover from lesions than others (Bartolomeo and Thiebaut de Schotten, under review).

Thus, pre-lesional brain structure may be inferred from the status of the healthy hemisphere after a unilateral stroke (Forkel et al., 2014), but this approach obviously cannot resolve the issue of individual differences in hemispheric asymmetries. However, longitudinal studies of patients with brain tumours before and after surgery may offer more possibilities (Charras et al., 2015; Shallice et al., 2010), despite caveats such as some level of uncertainty about the real extent of malfunctioning brain tissue, or phenomena of functional remodeling with low-grade gliomas (Bartolomeo, 2011). In neurosurgical patients, structural and functional neuroimaging evidence may be obtained before surgical excision, and may thus help interpret possible postoperative deficits by taking into proper account inter-individual differences in brain structure. 


\section{The critical importance of single case studies in cognitive neuroscience and neuropsychology}

\subsection{One patient at a time}

In principle, single patient studies should be ideally placed to deal with interindividual variability. If not all brains are anatomically and functionally homogeneous, then there is even less ground for the homogeneity required by group studies, which are already problematic under the universality assumption, because "there is no a priori classification schema that can be used to justify the assumption of homogeneity and allow valid inferences from patient group data" (Caramazza, 1986, p. 55).

Single case studies provide indeed a remarkable source of evidence (Shallice, 1979). They are instrumental for the generation of new research hypotheses, as individual patients may present patterns of anatomical lesions and cognitive deficits unimaginable otherwise. Single case studies may be crucial for suggesting models, which can then be tested with other patients or evidence from other experimental work (including neuroimaging, neurostimulation, and animal neurophysiology). Single case studies can also provide proofs of concept for cognitive models of the intact mind/brain, as well as indications of the causal relations between lesions and symptoms. Moreover, rare conditions such as word deafness or pure alexia can in practice only be studied as case reports, because it would be impossible to recruit many of such patients in a reasonable time. Also, single case studies allow for an extended behavioral description, which would often be too labor-intensive in groups of patients. Finally, it is important to note that the excellent level of detail of anatomical study, which is now possible thanks to cutting-edge neuroimaging techniques, is only applicable to single patients, or to small series of patients, and not to large groups. In group studies, lesions need to be plotted, or "normalized", on a standard brain, which can only approximate the 
spatial arrangement of real, individual brains (Bartolomeo, 2006).

Thus, far from being 'merely anecdotal', case studies can bring a substantial contribution to cognitive neuroscience (Newcombe and Marshall, 1988). Nonetheless, caution should be exerted when applying the implications of data from single-cases studies to models of normal cognition (Della Sala et al., 1991). When a patient's pattern of performance does not fit a pre-existing model, we may either reject the patient or change/reject the current model. Patients may be excluded if there is evidence of multiple deficits, multiple lesions or idiosyncratic strategies, which may or may not reflect an underlying pathology. On the other hand, changing the model requires the rejection of a large body of data supporting that model and might be more difficult. This option may however be encouraged by cumulative evidence from several different patients (Della Sala et al., 1991). In a Bayesian perspective, to reject an established model requires strong new evidence (Goodman et al., 2016), while rejecting the pattern of performance of a single patient as theoretically informative may require less of a support, because of the sources of uncertainty described above.

Thus, the risk of building neurocognitive models on the exclusive basis of unreplicated single cases should be considered, because of the possibility of committing Botallo's error. This risk was already mentioned by Caramazza, who stated that " $[\mathrm{t}]$ he pattern of performance of a single patient can be used to propose a specific hypothesis, but ultimately, the evaluation of a model is based on the full range of available relevant evidence, including the performance of other patients and normal subjects" (Caramazza, 1986, p. 60). However, as Shallice noted, "[i]f each patient is treated as unique, then replication of an observation on another patient becomes impossible...". And yet, replication of single cases remains crucial, because "the subject of a case study could be a patient who has developed an idiosyncratic coping strategy of could even be a hysteric or malingerer" (Shallice, 1988, p. 31). 
Indeed, in our reading of the literature there are examples of single case studies that have made their way to neuropsychology textbooks without sufficient replication. For instance, in the domain of visual neglect double dissociations of performance in single patients have sometimes been taken as conclusive evidence for the independence of the relative cognitive abilities. And yet, individual strategies of compensation may well play a role in neglect dissociations. As stressed by Ennio De Renzi (1982), neglect has a unique position in neuropsychology, in that the very same stimulus may be processed or not depending on its position in space. Thus, even a subtle change in the patient's exploration strategy may dramatically change his or her performance.

\subsection{The case of imaginal neglect}

A historical example is that of imaginal, or representational, neglect. In the study that arguably started the cognitive neuropsychology of spatial neglect, Bisiach and Luzzatti (1978) described two Milanese patients who, when describing from memory the Piazza del Duomo, forgot to mention the details situated on the left side of their mental image of the Piazza. On the basis of these single cases and of subsequent group studies, Bisiach et al. concluded that neglect resulted from "a representational map reduced to one half" (Bisiach et al., 1981, p. 549). However, the generality of this conclusion was put into question when a multiple single case study, in which patients' performance was analyzed both as groups and as single cases, showed signs of imaginal neglect only in about a third of right brain-damaged patients with visual neglect (Bartolomeo et al., 1994). The relative rarity of imaginal neglect, repeatedly confirmed afterwards (Bourlon et al., 2011; Bourlon et al., 2008), leaves however open the question of its origin. Imaginal neglect might depend on additional deficits, such as deficits of spatial working memory (Rode et al., 2007) or of endogenous orienting of attention (Bourlon et al., 2011). However, there are other possibilities. One is the possibility of individual differences on visual imagery abilities; perhaps those who experience more "vivid" visual 
images are also those more likely to suffer from stroke-induced imaginal neglect, because then right-sided visual images would tend to capture patients' attention in a similar way as right-sided visual objects (Rastelli et al., 2008). Another possibility concerns individual differences in compensation/recovery, which might leave some patients with neglect in one, but not in the other, modality. This, however, was found to be the case for patients who initially showed an association of visual and imaginal neglect, and later recovered only from visual neglect, while retaining signs of imaginal neglect (Bartolomeo and Chokron, 2001; Bartolomeo et al., 1994). Be that as it may, these considerations should be kept in mind before concluding that visual and imaginal neglect are entirely dissociable entities.

\section{Dealing with variation in neuropsychological single cases}

Unfortunately, there are no definitive answers to the questions raised above, which would require a reliable assessment of a patient's pre-morbid anatomy and function, in order to differentiate pre-existing anomalies from acquired defects. Some suggestions seem, however, in order.

\subsection{Research reproducibility}

First, the importance of replication should be stressed. As in the classical case of Botallo's error, replications (or lack thereof) can help to reveal the cognitive deficits that are stable across variations in anatomy, in function and in lesion etiology and consequences. Three different aspects of research reproducibility can be distinguished (Goodman et al., 2016): (1) methods reproducibility, whereby the same procedures can be exactly repeated thanks to a detailed description of the methods; (2) results reproducibility, which refers to independent replication of the same results with closely matched procedures; and, most importantly, (3) inferential reproducibility, the drawing of qualitatively similar conclusions from independent replication of or reanalysis of a previous study. For example, a study could 
reproduce exactly the same results, but accommodate a different interpretation and different theoretical conclusions. The requirement of inferential reproducibility is even more mandatory when a single case study seems to falsify a well-accepted model, or to suggest a completely novel scenario. As mentioned before, in a Bayesian perspective, claims that were highly unlikely before an experiment require stronger new evidence than claims more consistent with previous evidence (Goodman et al., 2016).

Studies of groups of patients do not seem, however, appropriate to attain inferential reproducibility of single case studies (see Caramazza, 1986). Multiple single cases might instead offer the possibility of replication while avoiding the averaging problems of studies of groups of patients, which erase individual performance patterns (Caramazza and McCloskey, 1988).

Still, attempts to replicate studies often languish unpublished in personal file drawers (Yong, 2012), like the attempts to publish negative results (Rosenthal, 1979). This phenomenon is known as the 'file drawer problem': scientific journals entrench themselves behind the publication of positive novel results and, in doing so, report only a tiny minority (around 5\%) of the studies that are actually conducted, disregarding how scientifically essential those unreported findings could be (Fanelli, 2011). If this publication barrier is lifted, then publishing more single case reports would give rise to more replications, across different lesion etiologies and tests.

\subsection{Establishing norms for brain anatomy, function and dysfunction}

Thanks to recent advances in neuroimaging, individual variations in brain anatomy and functional organization can now be studied in detail (Dubois and Adolphs, 2016). This opens the possibility of establishing anatomical and functional norms for neurologically intact population, much like the behavioral norms existing for neuropsychological tests. Thus, it will be feasible to analyze fMRI data of the individual in light of their distribution in a normative 
sample (Dubois and Adolphs, 2016). In this way, the pre-existing individual variability of a single patient might be inferred by comparing the anatomy and functional organization of the patient's intact brain regions (e.g., the healthy hemisphere in case of unilateral lesions) to the population norms. If a single-case is sampled from the edge of the distribution, far from the average or from the mode, any conclusion based on it cannot be validly generalized to the entire population. However, while such a case cannot represent the population, it can still teach us something about the population's variability, which is equally important and may further constrain neurocognitive models. This approach does not completely resolve the issue of premorbid variability, but may constitute a preliminary step for its assessment.

Such norms would be beneficial not only to the study of patients but also for the neurologically intact population. Large databases like the human connectome project (http://www.humanconnectomeproject.org) for brain anatomy or Neurosynth (http://neurosynth.org/) for functional neuroimaging (Yarkoni et al., 2011) are an important starting point for establishing such norms.

It would be also important, although undoubtedly even more difficult, to try to establish norms for lesions causing cognitive impairments. This might be accomplished by evaluating a substantial number of single patients, consider where the intact regions of their brain lay on the histogram of the normal population's distribution (while taking into account the anatomical variability without any normalization), and incorporate the behavioral pattern and the brain lesion associated with each case. Multivariate approaches such as decoding might be used to process individual data across several dimensions (anatomy, functional organization, brain lesion, cognitive performance), while exploiting individual variability to test theoretical models. A similar strategy has been proposed for lesion-symptom mapping after stroke (Mah et al., 2014). However, it would be too labor-intensive to collect detailed 
behavioral data on many patients. The development of sensitive and reliable computerized test batteries might help approaching this goal.

Such large datasets might enable us to make general inferences from the study of single patients, as well as to find meaningful patterns across data (anatomical, functional, etc.) and across individual subjects. For example, individual patterns of structural connectivity might be used to predict behavioral performance (Kanai and Rees, 2011), or patterns of functional activations (Thiebaut de Schotten et al., 2014a). Specific patterns of results for single patients might also be used to predict their clinical outcome.

\section{Conclusions}

It should be clear by now that the considerations raised here are not meant to imply that single-case studies of neurological patients are unable to provide robust evidence on the functioning of cognitive systems and their neural bases. On the contrary, there are compelling reasons to continue using the single-case research approach, because of its irreplaceable causal evidence, not only to establish functional cognitive mechanisms (Caramazza and Coltheart, 2006), but also for lesion-symptom mapping (Bartolomeo, 2011).

Instead, Botallo's error stands as a warning against hasty conclusions from single case reports, and a reminder that one should always yearn for replication, despite the hostile environment of a publication system heavily biased towards novelty. Individual patients may show exotic patterns of performance "sexy" enough to make their way onto high-impact journals, but in the absence of replication one cannot exclude the influence of idiosyncratic variations (or downright pre-existing defects) of the mind/brain. Thus, drawing general conclusions from single cases requires inferential reproducibility through the detailed study of multiple single patients. In perspective, as our techniques now reach a resolution capable to detect inter-individual variations in brain anatomy and functional organization, availability of 
large datasets may enable us to draw stronger conclusions when evaluating neurocognitive models based on single patient studies. 


\section{References}

Andrade, K., Kas, A., Samri, D., Sarazin, M., Dubois, B., Habert, M.O., Bartolomeo, P. Visuospatial deficits and hemispheric perfusion asymmetries in posterior cortical atrophy. Cortex 49 (4): 940-947, 2013.

Andrade, K., Kas, A., Valabrègue, R., Samri, D., Sarazin, M., Habert, M.O., Dubois, B., Bartolomeo, P. Visuospatial deficits in posterior cortical atrophy: structural and functional correlates. Journal of Neurology, Neurosurgery and Psychiatry 83 (9): 860863, 2012.

Bartley, A.J., Jones, D.W., Weinberger, D.R. Genetic variability of human brain size and cortical gyral patterns. Brain 120 (2): 257-269, 1997.

Bartolomeo, P. A parieto-frontal network for spatial awareness in the right hemisphere of the human brain. Archives of Neurology 63: 1238-1241, 2006.

Bartolomeo, P. The quest for the 'critical lesion site' in cognitive deficits: problems and perspectives. Cortex 47 (8): 1010-1012, 2011.

Bartolomeo, P. Attention disorders after right brain damage: Living in halved worlds. Springer-Verlag: London, 2014.

Bartolomeo, P., Chokron, S. Levels of impairment in unilateral neglect. in: Boller, F., Grafman, J. (Eds.), Handbook of Neuropsychology. Elsevier Science Publishers: Amsterdam, 2001. pp. 67-98.

Bartolomeo, P., D'Erme, P., Gainotti, G. The relationship between visuospatial and representational neglect. Neurology 44: 1710-1714, 1994.

Bartolomeo, P., Thiebaut de Schotten, M. Let thy left brain know what thy right brain doeth: inter-hemispheric compensation of functional deficits after brain damage. Neuropsychologia, under review. 
Bisiach, E., Capitani, E., Luzzatti, C., Perani, D. Brain and conscious representation of outside reality. Neuropsychologia 19: 543-551, 1981.

Bisiach, E., Luzzatti, C. Unilateral neglect of representational space. Cortex 14: 129-133, 1978.

Botallo, L. De Catarrho commentarius. Apud Bernardum Turrisanum: Paris, 1564.

Bourlon, C., Duret, C., Pradat-Diehl, P., Azouvi, P., Loeper-Jény, C., Merat-Blanchard, M., Levy, C., Chokron, S., Bartolomeo, P. Vocal response times to real and imagined stimuli in spatial neglect: A group study and single-case report. Cortex 47 (5): 536-546, 2011.

Bourlon, C., Pradat-Diehl, P., Duret, C., Azouvi, P., Bartolomeo, P. Seeing and imagining the “same” objects in unilateral neglect. Neuropsychologia 46: 2602-2606, 2008.

Bowers, D., Heilman, K.M. Pseudoneglect: Effects of hemispace on a tactile line bisection task. Neuropsychologia 18: 491-498, 1980.

Cabeza, R., Rao, S.M., Wagner, A.D., Mayer, A.R., Schacter, D.L. Can medial temporal lobe regions distinguish true from false? An event-related functional MRI study of veridical and illusory recognition memory. Proceedings of the National Academy of Sciences 98 (8): 4805-4810, 2001.

Caramazza, A. On drawing inferences about the structure of normal cognitive systems from the analysis of patterns of impaired performance: the case for single-patient studies. Brain and Cognition 5 (1): 41-66, 1986.

Caramazza, A., Coltheart, M. Cognitive neuropsychology twenty years on. Cognitive Neuropsychology 23 (1): 3-12, 2006.

Caramazza, A., McCloskey, M. The case for single-patient studies. Cognitive Neuropsychology 5 (5): 517-527, 1988.

Carrera, E., Tononi, G. Diaschisis: past, present, future. Brain, 2014. 
Catani, M., Allin, M.P., Husain, M., Pugliese, L., Mesulam, M.-M., Murray, R.M., Jones, D.K. Symmetries in human brain language pathways correlate with verbal recall. Proc Natl Acad Sci U S A 104 (43): 17163-17168, 2007.

Charras, P., Herbet, G., Deverdun, J., de Champfleur, N.M., Duffau, H., Bartolomeo, P., Bonnetblanc, F. Functional reorganization of the attentional networks in low-grade glioma patients: A longitudinal study. Cortex 63: 27-41, 2015.

Charras, P., Lupiáñez, J., Bartolomeo, P. Assessing the weights of visual neglect: a new approach to dissociate defective symptoms from productive phenomena in length estimation. Neuropsychologia 48 (11): 3371-3375, 2010.

Charras, P., Lupiáñez, J., Migliaccio, R., Toba, M.N., Pradat-Diehl, P., Duret, C., Bartolomeo, P. Dissecting the component deficits of perceptual imbalance in visual neglect: Evidence from horizontal-vertical length comparisons. Cortex 48 (5): 540-552, 2012. Chiu, V.W., Lee, T. Detection of malingering behavior at different levels of task difficulty in Hong Kong Chinese. Rehabilitation Psychology 47 (2): 194, 2002.

Chokron, S., Imbert, M. Influence of reading habits on line bisection. Cognitive Brain Research 1: 219-222, 1993.

Ciaraffa, F., Castelli, G., Parati, E.A., Bartolomeo, P., Bizzi, A. Visual neglect as a disconnection syndrome? A confirmatory case report. Neurocase 19 (4): 351-359, 2013.

Crawford, J.R., Garthwaite, P.H. Investigation of the single case in neuropsychology: confidence limits on the abnormality of test scores and test score differences. Neuropsychologia 40 (8): 1196-1208, 2002.

De Renzi, E. Disorders of space elaboration and cognition. John Wiley \& Sons: New York, 1982.

Dehaene, S., Cohen, L. The unique role of the visual word form area in reading. Trends in Cognitive Sciences 15 (6): 254-262, 2011. 
Dehaene, S., Cohen, L., Morais, J., Kolinsky, R. Illiterate to literate: behavioural and cerebral changes induced by reading acquisition. Nature Reviews Neuroscience 16 (4): 234-244, 2015.

Dehaene, S., Pegado, F., Braga, L.W., Ventura, P., Nunes Filho, G., Jobert, A., DehaeneLambertz, G., Kolinsky, R., Morais, J., Cohen, L. How learning to read changes the cortical networks for vision and language. Science 330 (6009): 1359-1364, 2010.

Doricchi, F., \& Tomaiuolo, F. (2003). The anatomy of neglect without hemianopia: a key role for parietal-frontal disconnection? NeuroReport, 14(17), 2239-2243.

Della Sala, S., Logie, R., Marchetti, C., Wynn, V. Case studies in working memory: A case for single cases? Cortex 27 (2): 169-191, 1991.

Draganski, B., Gaser, C., Busch, V., Schuierer, G., Bogdahn, U., May, A. Neuroplasticity: changes in grey matter induced by training. Nature 427 (6972): 311-312, 2004.

Dubois, J., Adolphs, R. Building a Science of Individual Differences from fMRI. Trends in Cognitive Sciences 20 (6): 425-443, 2016.

Fanelli, D. Negative results are disappearing from most disciplines and countries. Scientometrics 90 (3): 891-904, 2011.

Farah, M.J., Wolpe, P.R. Monitoring and manipulating brain function: New neuroscience technologies and their ethical implications. Hastings Center Report 34 (3): 35-45, 2004.

Finn, E.S., Shen, X., Scheinost, D., Rosenberg, M.D., Huang, J., Chun, M.M., Papademetris, X., Constable, R.T. Functional connectome fingerprinting: identifying individuals using patterns of brain connectivity. Nature Reviews Neuroscience: -, 2015.

Forkel, S.J., Thiebaut De Schotten, M., Dell\&apos;Acqua, F., Kalra, L., Murphy, D.G.M., Williams, S.C.R., Catani, M. Anatomical predictors of aphasia recovery: a tractography study of bilateral perisylvian language networks. Brain 137 (7): 2027-2039, 2014.

Fransson, S.G. The Botallo mystery. Clin Cardiol 22 (6): 434-436, 1999. 
Godefroy, O., Duhamel, A., Leclerc, X., Saint Michel, T., Henon, H., Leys, D. Brainbehaviour relationships. Some models and related statistical procedures for the study of brain-damaged patients. Brain 121 ( Pt 8): 1545-1556, 1998.

Goodman, S.N., Fanelli, D., Ioannidis, J.P.A. What does research reproducibility mean? Science translational medicine 8 (341): 341ps312-341ps312, 2016.

Horikawa, T., Tamaki, M., Miyawaki, Y., Kamitani, Y. Neural decoding of visual imagery during sleep. Science 340 (6132): 639-642, 2013.

Jewell, G., McCourt, M.E. Pseudoneglect: a review and meta-analysis of performance factors in line bisection tasks. Neuropsychologia 38 (1): 93-110, 2000.

Kanai, R., Rees, G. The structural basis of inter-individual differences in human behaviour and cognition. Nature Reviews Neuroscience 12 (4): 231-242, 2011.

Langleben, D.D., Schroeder, L., Maldjian, J., Gur, R., McDonald, S., Ragland, J., O'Brien, C., Childress, A.R. Brain activity during simulated deception: an event-related functional magnetic resonance study. Neuroimage 15 (3): 727-732, 2002.

Leibovitch, F.S., Black, S.E., Caldwell, C.B., Ebert, P.L., Ehrlich, L.E., Szalai, J.P. Brainbehavior correlations in hemispatial neglect using CT and SPECT: the Sunnybrook Stroke Study. Neurology 50 (4): 901-908, 1998.

Lohmann, G., von Cramon, D.Y., Steinmetz, H. Sulcal Variability of Twins. Cerebral Cortex 9 (7): 754-763, 1999.

Lunven, M., Thiebaut De Schotten, M., Bourlon, C., Duret, C., Migliaccio, R., Rode, G., Bartolomeo, P. White matter lesional predictors of chronic visual neglect: a longitudinal study. Brain 138 (Pt 3): 746-760, 2015.

Maguire, E.A., Gadian, D.G., Johnsrude, I.S., Good, C.D., Ashburner, J., Frackowiak, R.S., Frith, C.D. Navigation-related structural change in the hippocampi of taxi drivers. Proc Natl Acad Sci U S A 97 (8): 4398-4403, 2000. 
Mah, Y.H., Husain, M., Rees, G., Nachev, P. Human brain lesion-deficit inference remapped. Brain 137 (Pt 9): 2522-2531, 2014.

McCourt, M.E., Garlinghouse, M., Reuter-Lorenz, P.A. Unilateral visual cueing and asymmetric line geometry share a common attentional origin in the modulation of pseudoneglect. Cortex 41 (4): 499-511, 2005.

McCourt, M.E., Jewell, G. Visuospatial attention in line bisection: stimulus modulation of pseudoneglect. Neuropsychologia 37 (7): 843-855, 1999.

Migliaccio, R., Agosta, F., Toba, M.N., Samri, D., Corlier, F., de Souza, L.C., Chupin, M., Sharman, M., Gorno-Tempini, M.L., Dubois, B., Filippi, M., Bartolomeo, P. Brain networks in posterior cortical atrophy: A single case tractography study and literature review. Cortex 48 (10): 1298-1309, 2012.

Mongelli, V., Dehaene, S., Vinckier, F., Peretz, I., Bartolomeo, P., Cohen, L. Music and words in the visual cortex: the impact of musical expertise. Cortex, 2016.

Moore, K.L. Meaning of “normal”. Clinical Anatomy 2 (4): 235-239, 1989.

Newcombe, F., Marshall, J.C. Idealisation meets psychometrics: The case for the right groups and the right individuals. Cognitive Neuropsychology 5 (5): 549-564, 1988.

Ossandón, J.P., Onat, S., König, P. Spatial biases in viewing behavior. Journal of Vision 14 (2): $20-20,2014$.

Rastelli, F., Funes, M.J., Lupiáñez, J., Duret, C., Bartolomeo, P. Left neglect: Is the disengage deficit space- or object-based? Experimental Brain Research 187 (3): 439-446, 2008.

Rode, G., Revol, P., Rossetti, Y., Boisson, D., Bartolomeo, P. Looking while imagining: The influence of visual input on representational neglect. Neurology 68 (6): 432-437, 2007.

Rosenthal, R. The file drawer problem and tolerance for null results. Psychological bulletin 86 (3): $638,1979$. 
Shallice, T. Case study approach in neuropsychological research. Journal of clinical and experimental neuropsychology 1 (3): 183-211, 1979.

Shallice, T. From Neuropsychology to Mental Structure. Cambridge University Press: New York, 1988.

Shallice, T., Mussoni, A., D'Agostino, S., Skrap, M. Right posterior cortical functions in a tumour patient series. Cortex, 2010.

Thiebaut de Schotten, M., Cohen, L., Amemiya, E., Braga, L.W., Dehaene, S. Learning to read improves the structure of the arcuate fasciculus. Cereb Cortex 24 (4): 989-995, 2014a.

Thiebaut de Schotten, M., Dell'Acqua, F., Forkel, S.J., Simmons, A., Vergani, F., Murphy, D.G.M., Catani, M. A lateralized brain network for visuospatial attention. Nature Neuroscience 14 (10): 1245-1246, 2011.

Thiebaut de Schotten, M., Tomaiuolo, F., Aiello, M., Merola, S., Silvetti, M., Lecce, F., Bartolomeo, P., Doricchi, F. Damage to white matter pathways in sub-acute and chronic spatial neglect: a group study and two single-case studies with complete virtual "invivo“" tractography dissection. Cerebral Cortex 24 (3): 691-706, 2014 b.

Thiebaut de Schotten, M., Urbanski, M., Duffau, H., Volle, E., Levy, R., Dubois, B., Bartolomeo, P. Direct evidence for a parietal-frontal pathway subserving spatial awareness in humans. Science 309 (5744): 2226-2228, 2005.

Thomas, C., Avidan, G., Humphreys, K., Jung, K.-j., Gao, F., Behrmann, M. Reduced structural connectivity in ventral visual cortex in congenital prosopagnosia. Nature Neuroscience 12 (1): 29-31, 2009.

Toba, M.N., Cavanagh, P., Bartolomeo, P. Attention biases the perceived midpoint of horizontal lines. Neuropsychologia 49 (2): 238-346, 2011. 
Urbanski, M., Bartolomeo, P. Line bisection in left neglect: The importance of starting right. Cortex 44 (7): 782-793, 2008.

Urbanski, M., Thiebaut de Schotten, M., Rodrigo, S., Oppenheim, C., Touzé, E., Méder, J.F., Moreau, K., Loeper-Jeny, C., Dubois, B., Bartolomeo, P. DTI-MR tractography of white matter damage in stroke patients with neglect. Experimental Brain Research 208 (4): 491-505, 2011.

Vallar, G., Bello, L., Bricolo, E., Castellano, A., Casarotti, A., Falini, A., Riva, M., Fava, E., Papagno, C. Cerebral correlates of visuospatial neglect: a direct cerebral stimulation study. Hum Brain Mapp 35 (4): 1334-1350, 2014.

Verdon, V., Lovblad, K.-O., Hauert, C.-A., Vuilleumier, P. Neuroanatomical basis of hemispatial neglect components using Voxel-based Lesion Symptom Mapping. 2nd Meeting of the European Societies of Neuropsychology: Toulouse, France, 2006. p. 277.

Vogel, E.K., Awh, E. How to Exploit Diversity for Scientific Gain Using Individual Differences to Constrain Cognitive Theory. Current Directions in Psychological Science 17 (2): 171-176, 2008.

Wang, L., Mruczek, R.E., Arcaro, M.J., Kastner, S. Probabilistic maps of visual topography in human cortex. Cerebral Cortex: bhu277, 2014.

Yarkoni, T., Poldrack, R.A., Nichols, T.E., Van Essen, D.C., Wager, T.D. Large-scale automated synthesis of human functional neuroimaging data. Nature methods 8 (8): 665-670, 2011.

Yong, E. In the wake of high profile controversies, psychologists are facing up to problems with replication. Nature 483: 298-300, 2012. 


\section{Figure Legends}

Fig. 1. Leonardo Botallo (ca. 1519-1587/1588)

Acknowledgments. This work has received funding from the Israeli Science Foundation to TSM (ISF 57/15) and from the program "Investissements d'Avenir" ANR-10-IAIHU-06. 